\title{
Mechanical properties and microstructure evolution of high-manganese (0.9 C - 13.95 Mn) steel during aging
}

\author{
Omar Ben lenda ${ }^{1 *}$, Sara Benmaziane ${ }^{1}$, Ahmed Tara $^{2}$, and Elmadani Saad ${ }^{1}$ \\ ${ }^{1}$ Laboratory of Physical-Chemistry of Processes and Materials, Hassan $1^{\text {st }}$ University, Faculty of Sciences and Technology Settat, \\ Settat, Morocco \\ ${ }^{2}$ L'institut de Thermique, Mécanique, Matériaux (ITheMM) EA 7548, Université de Reims Champagne-Ardenne, Reims, France
}

\begin{abstract}
The influence of temperature on the structural and mechanical properties of the $(0.9 \mathrm{C}-13.95 \mathrm{Mn})$ steel was investigated in this work. The high-manganese steel has underwent aging treatments at temperatures $700,750,800$ and $850^{\circ} \mathrm{C}$ for different times. The experimental techniques used are hardness test, scanning electron microscopy, optical microscopy and X-ray diffraction. The mechanical behavior and microstructural evolution of the high-manganese steel during aging are almost the same. The aging of the high-manganese steel was characterized by a rapid hardening while the overaging by a slow softening. In aging, the dispersion of fine $\mathrm{M}_{7} \mathrm{C}_{3}$ carbides in the austenite led to an increase in hardness. In overaging, the softening was caused by the coarsening of the $\mathrm{M}_{7} \mathrm{C}_{3}$ carbides.
\end{abstract}

\section{Introduction}

The austenitic manganese steels are ferrous alloys containing approximately 1.0 to $1.4 \%$ of carbon and 10 to $14 \%$ manganese [1]. The original austenitic manganese steel invented by Sir Robert Hadfield in 1882 contains $1.25 \%$ carbon and $12 \%$ manganese [2]. This steels are used in various fields such as ore processing, earthmoving, mining, railroading, lumbering, ... etc [3].

Various modifications of the original austenitic manganese steel have been proposed, but just a few patents have been adopted as significant improvements [4]. They generally involve variations in carbon and manganese content, with or without the addition of elements such as chromium, molybdenum, vanadium, nickel, titanium and bismuth [5]. Several researches have been performed on the manganese steels in order to study the influence of temperature [6 - 10] or composition [11 - 14] on their mechanical and structural properties.

The microstructure obtained after aging process depend on the steel composition and the heat treatment parameters (i.e. time and temperature) $[15,16]$. The amount, morphology, number and distribution of carbides have a great impact on the steels mechanical properties and their service life [17]. For low temperature aging (less than $400{ }^{\circ} \mathrm{C}$ ), the manganese steels does not exhibit significant transformations of the microstructure. In contrast, for high temperature aging (above $400{ }^{\circ} \mathrm{C}$ ), the studies shows the carbides precipitation at grain boundaries and in matrix with different morphologies [18 - 21].
The manganese steels are used in many industries because of their mechanical characteristics. They combine excellent wear resistance with high ductility and strength [22]. However, under severe working conditions, these steels deteriorate due to microstructural changes such as intermetallic phases' formation, carbides growth, microcrack propagation ... etc.

It is important to understand the changes that occur in the steels during prolonged aging. In this context, the main objective of this study is to understand the longterm aging mechanism of the high-manganese (0.9 C - 13.95 Mn) steel.

\section{Materials and Methods}

\subsection{Chemical composition and heat treatments of the (0.9 C - 13.95 Mn) steel}

The as-received steel contains essentially $0.9 \%$ carbon (weight percentage) and $13.95 \%$ manganese. The chemical elements composition constituting the $(0.9 \mathrm{C}-13.95 \mathrm{Mn})$ steel is given in Table 1 .

Table 1. The chemical composition of the $(0.9 \mathrm{C}-13.95 \mathrm{Mn})$ steel.

\begin{tabular}{|c|c|c|c|c|c|c|c|}
\hline $\mathrm{Fe}$ & $\mathrm{C}$ & $\mathrm{Mn}$ & $\mathrm{Si}$ & $\mathrm{Cr}$ & $\mathrm{Mo}$ & $\mathrm{Ni}$ & $\mathrm{Cu}$ \\
\hline 81.87 & 0.90 & 13.95 & 0.79 & 1.90 & 0.08 & 0.21 & 0.30 \\
\hline
\end{tabular}

\footnotetext{
* Corresponding author: o.benlenda@uhp.ac.ma
} 
The phase diagram of the $(0.9 \mathrm{C}-13.95 \mathrm{Mn})$ steel was calculated by ProCast ${ }^{\circledR}$ software. Figure 1 shows the fraction of liquid, austenite and $\mathrm{M}_{7} \mathrm{C}_{3}$ carbides for a range temperature from 600 to $1400^{\circ} \mathrm{C}$.

From phase fractions versus temperature diagram, the high-manganese steel is biphasic composed of the austenite and the $\mathrm{M}_{7} \mathrm{C}_{3}$ carbides at temperatures 700 , 750,800 and $850{ }^{\circ} \mathrm{C}$.

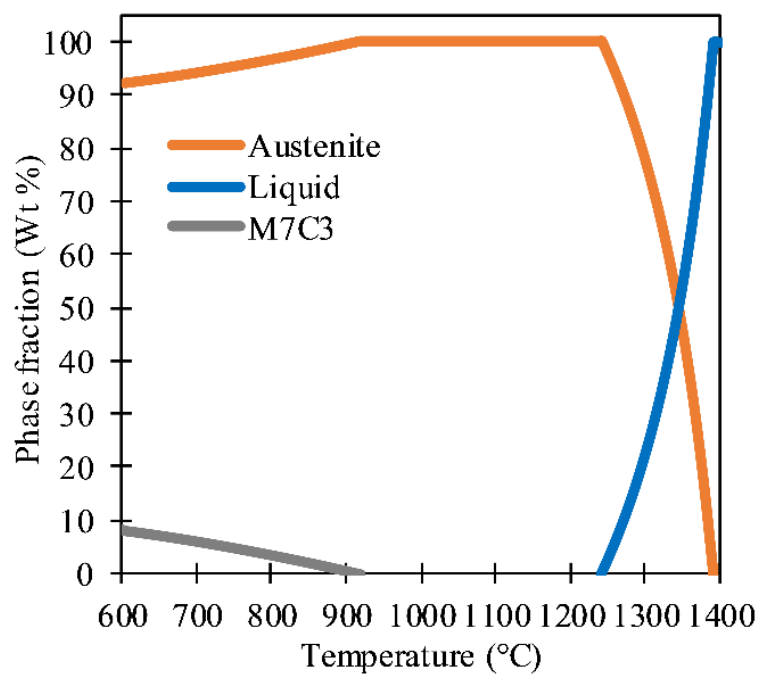

Fig. 1. Phases fraction as a function of temperature for the $(0.9 \mathrm{C}-13.95 \mathrm{Mn})$ steel.

First, the $(0.9 \mathrm{C}-13.95 \mathrm{Mn})$ steel is aged at four different temperatures $700,750,800$ and $850{ }^{\circ} \mathrm{C}$ for different times. Then, the samples $\left(15 * 15 * 10 \mathrm{~mm}^{3}\right)$ after each heat treatment are water quenched.

\subsection{Hardness Test}

The hardness profiles of the $(0.9 \mathrm{C}-13.95 \mathrm{Mn})$ steel during aging and overaging are obtained with a TESTWELL hardness tester. The hardness evaluation method used is Rockwell C (HRC) (the indenter is a spherical diamond-tipped cone with a $120^{\circ}$ angle and $0.2 \mathrm{~mm}$ tip radius and a total load of $150 \mathrm{Kgf}$ ) [23].

The hardness test protocol adopted consists of performing several indentations on the flat polished surface of the sample.

\subsection{Microscopic study}

The $(0.9 \mathrm{C}-13.95 \mathrm{Mn})$ steel microstructure was examined by a PHILIPS XL30 ESEM scanning electron microscopy coupled with energy dispersive spectroscopy (EDS) and a OPTIKA metallograph equipped with a AIPTEK high-resolution camera. The nital $2 \%$ solution ( $2 \mathrm{ml}$ of nitric acid $+98 \mathrm{ml}$ of ethanol) was used to etch the austenite and the $\mathrm{M}_{7} \mathrm{C}_{3}$ carbides [24].

\subsection{X-ray diffraction}

$\mathrm{X}$-ray diffraction spectra of the $(0.9 \mathrm{C}-13.95 \mathrm{Mn})$ steel samples are obtained using a BRUKER D8 Advance diffractometer of BRAGG-BRENTANO geometry. Monochromatic radiations are produced from copper tubes $(\mathrm{K} \alpha=1.5406 \AA$ ) operating at $40 \mathrm{kV}$ and $40 \mathrm{~mA}$. The scan interval $(2 \theta)$ is between 10 and $100^{\circ}$ with an angular step of $0.06^{\circ}$ per second.

The International Center for Diffraction Data (ICDD) cards used to identify the peaks are ${ }^{\circ}$ (31-0619) for the austenite and $\mathrm{n}^{\circ}$ (5-720) for the $\mathrm{M}_{7} \mathrm{C}_{3}$ carbides.

\section{Results and discussions}

\subsection{Hardness test}

Figure 2 shows the hardness evolution of the $(0.9 \mathrm{C}-13.95 \mathrm{Mn})$ steel aged at $700,750,800$ and 850 ${ }^{\circ} \mathrm{C}$ as a function of time. We can observe that the hardness-time curves consists of two steps (aging and overaging) at different aging temperatures. The aging of the $(0.9 \mathrm{C}-13.95 \mathrm{Mn})$ steel is characterized by a rapid increase and the overaging by a slow decrease of hardness.

It is also noted that, by increasing the aging temperatures, the maximum peak of the hardness-time curves decreases.

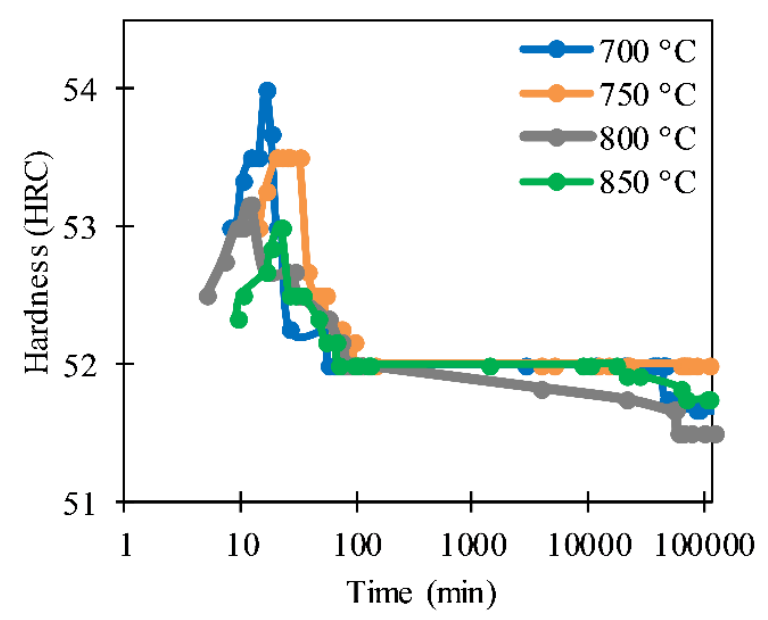

Fig. 2. Hardness versus time of the $(0.9 \mathrm{C}-13.95 \mathrm{Mn})$ steel at different aging temperatures.

\subsection{Microscopic study}

Figure 3 represent the metallographic observations of the $(0.9 \mathrm{C}-13.95 \mathrm{Mn})$ steel microstructure aged at 700 ${ }^{\circ} \mathrm{C}$ for different times.

Figure 3(a) show the $(0.9 \mathrm{C}-13.95 \mathrm{Mn})$ steel microstructure for 10 minutes of aging. In this optical image, we can observe an intergranular precipitation of the $\mathrm{M}_{7} \mathrm{C}_{3}$ carbides. The $\mathrm{M}_{7} \mathrm{C}_{3}$ carbides are initially located in the grain boundaries due to their high interfacial energy.

Figure 3(b) and 3(c) show the precipitation of the globular $\mathrm{M}_{7} \mathrm{C}_{3}$ carbides inside the grains after a holding time of 20 minutes. After a first intergranular precipitation of the $\mathrm{M}_{7} \mathrm{C}_{3}$ carbides, an intragranular precipitation occurs. We note that the precipitation of the $\mathrm{M}_{7} \mathrm{C}_{3}$ carbides is heterogeneous with the austenitic matrix. The appearance of these fine intragranular carbides, closely spaced and well distributed in the 
matrix, explains the increase in the hardness of the (0.9 C - $13.95 \mathrm{Mn})$ steel.

Significant interactions between the $\mathrm{M}_{7} \mathrm{C}_{3}$ carbides are observed for 60 minutes of aging (Figure 3(d)). The softening that occurs in the overaging is caused by the coarsening of the $\mathrm{M}_{7} \mathrm{C}_{3}$ carbides. The fine precipitates observed earlier will progressively disappear in favor of the larger ones and they will end up being few, large and widely spaced.
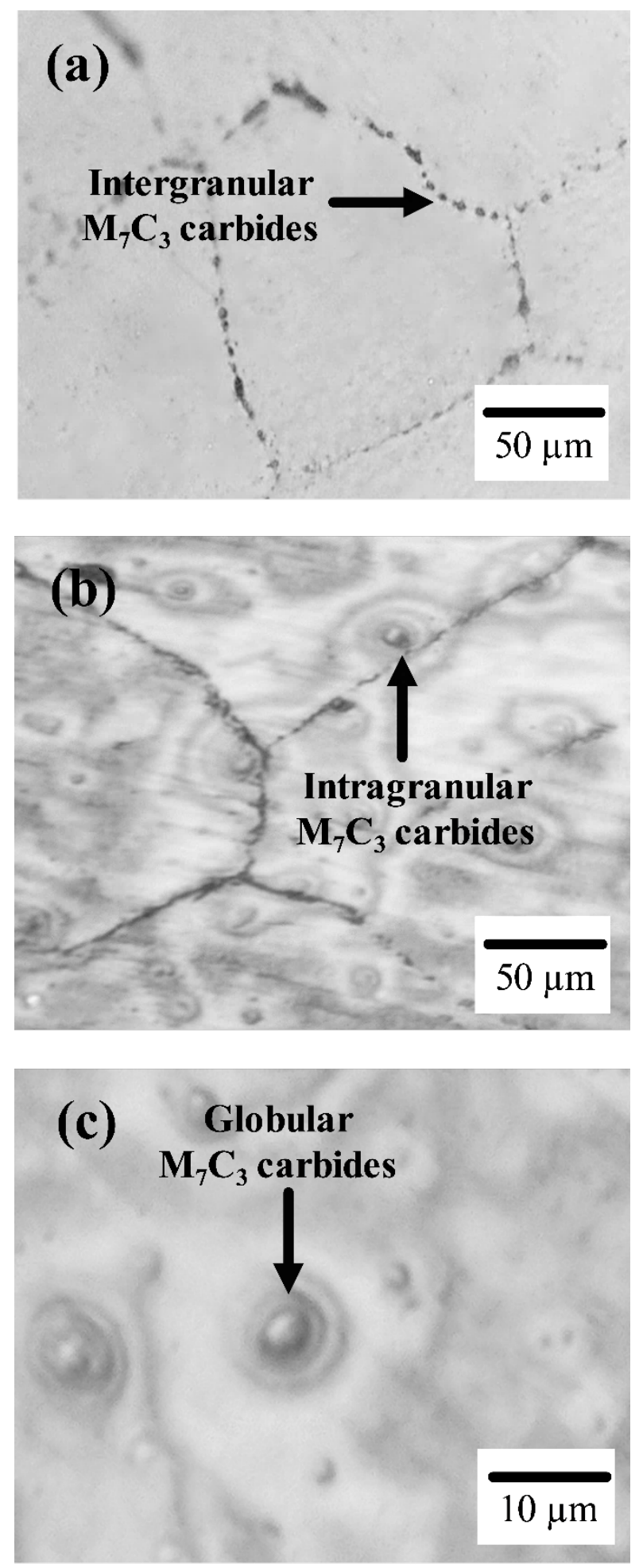

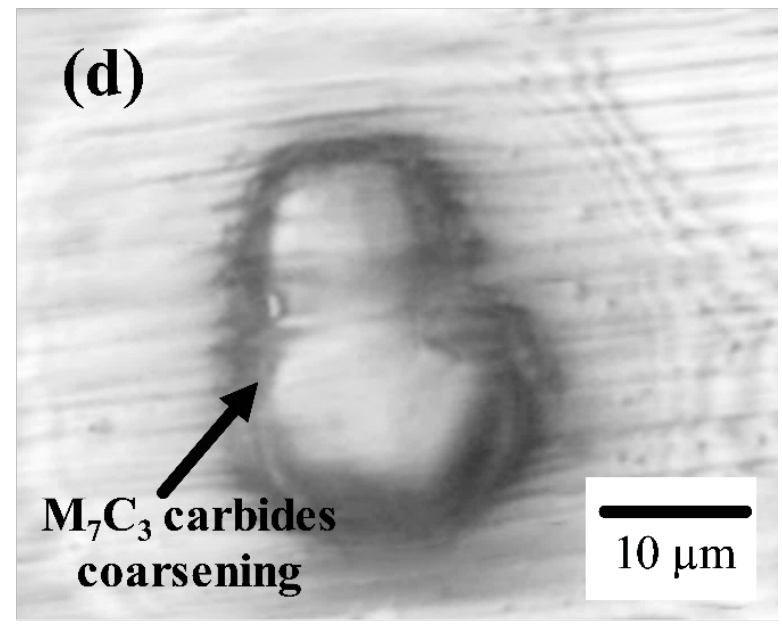

Fig. 3. Optical micrographs of the $(0.9 \mathrm{C}-13.95 \mathrm{Mn})$ steel microstructure aged at $700^{\circ} \mathrm{C}$ for (a) 10 , (b) and (c) 20 , and (d) 60 minutes.

Figure 4 shows a scanning electron microscope image of the $(0.9 \mathrm{C}-13.95 \mathrm{Mn})$ steel aged at $800{ }^{\circ} \mathrm{C}$ for 10 minutes. The results obtained corroborate with the phase fraction versus temperature diagram calculated by JMatPro ${ }^{\circledR}$ software (Figure 1). According to the EDS analysis (spectrum 1), the intergranular carbides are $\mathrm{M}_{7} \mathrm{C}_{3}$ type composed mainly of $39.06 \%$ iron, $54.23 \%$ chromium and $8.2 \%$ carbon.

We also observe that the area of the austenitic matrix adjacent to the $\mathrm{M}_{7} \mathrm{C}_{3}$ carbides are depleted in iron and chromium. The results (spectrum 2) indicate that it contains $69.23 \%$ iron and $0.68 \%$ chromium.

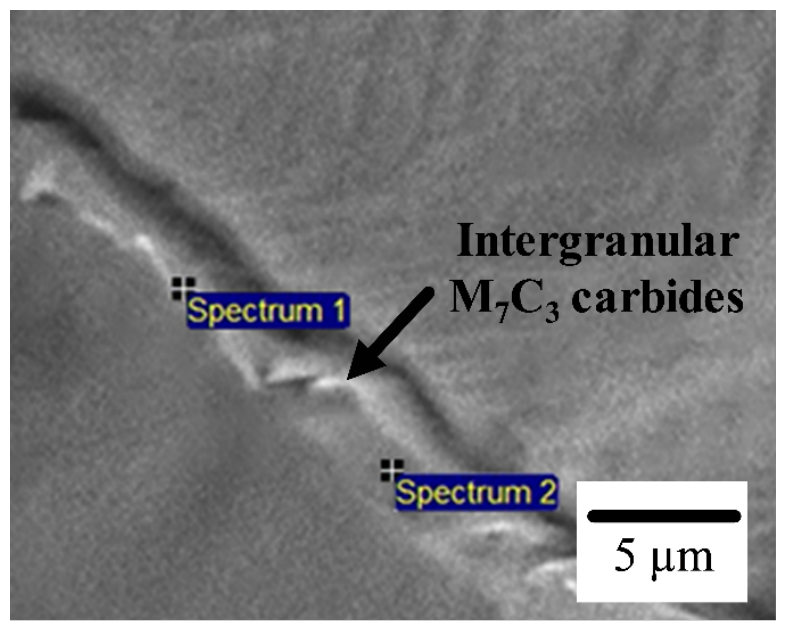

Fig. 4. SEM micrograph of the $(0.9 \mathrm{C}-13.95 \mathrm{Mn})$ steel microstructure aged at $800{ }^{\circ} \mathrm{C}$ for 10 minutes.

\subsection{X-ray diffraction}

Figure 5(a) shows the X-ray diffraction spectra of the $(0.9 \mathrm{C}-13.95 \mathrm{Mn})$ steel in aging at different temperatures. By increasing the temperature, the four spectra peaks do not exhibit any shift. Based on the ICDD cards, the peaks correspond to the austenite $(\gamma)$ (face-centered cubic structure, $\mathrm{a}=\mathrm{b}=\mathrm{c}=3.6 \mathrm{~nm}$ ).

It is also noted that no trace of the $\mathrm{M}_{7} \mathrm{C}_{3}$ carbides was detected by the $\mathrm{X}$-ray diffraction technique; this is probably due to their small size. Particles with small size 
and low fraction cannot be detected by this analytical technique, because the peak becomes very broad and it will be difficult to distinguish it from the background [25].

The spectra carried out in overaging of the (0.9 C - $13.95 \mathrm{Mn}$ ) steel (figure 5(b)) at different temperatures show good agreement with microscopic study. By comparing the spectra of the two stages, we notice the appearance of new peaks. The changes observed in the spectra are due to the formation of the $\mathrm{M}_{7} \mathrm{C}_{3}$ carbides (hexagonal structure, $\mathrm{a}=1.398 \mathrm{~nm}$ and $\mathrm{c}$ $=0.4523 \mathrm{~nm})$.

We are able to conclude that the increase of the $M_{7} C_{3}$ carbides fraction and their growth to reach a detectable size by this technique, leads to the appearance of peaks of visible intensity [26, 27].

(a)

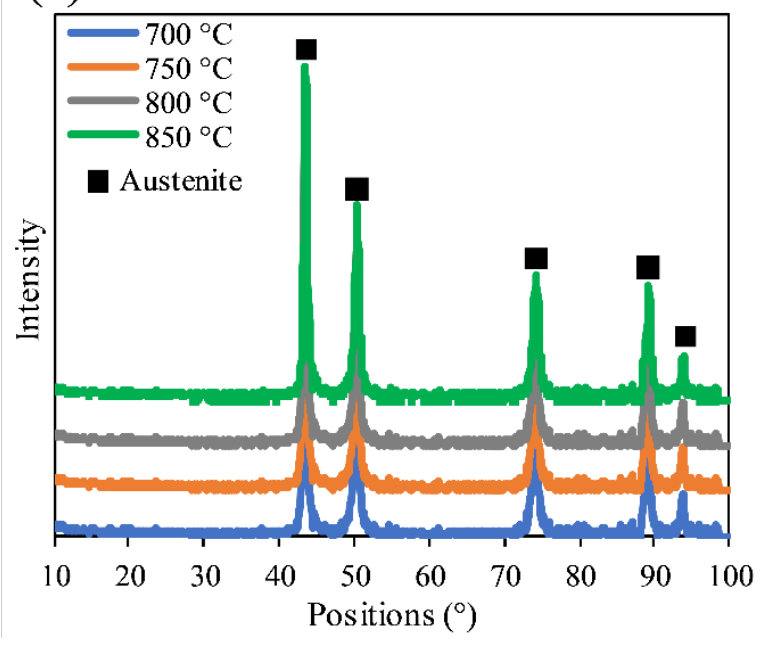

(b)

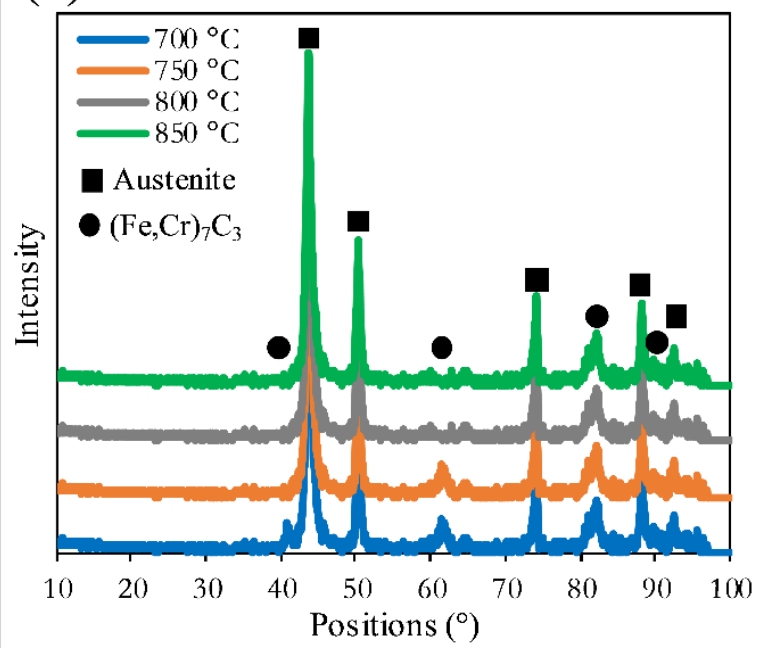

Fig. 5. X-ray diffraction spectra of the (0.9 C - $13.95 \mathrm{Mn})$ steel in (a) aging and (b) overaging at temperatures 700, 750, 800 and $850^{\circ} \mathrm{C}$.

\section{Conclusions}

In this paper, we studied the influence of thermal aging on the mechanical and structural behavior of the (0.9 C - 13.95 Mn) steel. The following conclusions can be drawn:
1. Through the hardness tests, we found that the hardness-time curves consist of two stages. The aging phase is characterized by a rapid increase in hardness while the overaging is accompanied by a slow decrease of this mechanical property.

2. Microscopic observations revealed that the precipitation of the $\mathrm{M}_{7} \mathrm{C}_{3}$ carbides occurs first at the grain boundaries and then propagate into the grains interior of the $(0.9 \mathrm{C}-13.95 \mathrm{Mn})$ steel. For shortterm aging, the intragranular $\mathrm{M}_{7} \mathrm{C}_{3}$ carbides are fine and closely spaced. For long-term aging, the intragranular $\mathrm{M}_{7} \mathrm{C}_{3}$ carbides are large and widely spaced.

\section{References}

1. E. Curiel-Reyna, J. Contreras, T. Rangel-Ortis, A. Herrera, L. Baños, A. del Real, M. E. Rodríguez, Mater. Manuf. Process. 23, 1 (2008)

2. J. R. Davis, Alloying: understanding the basics (ASM International, Materials Park Ohio, 2001)

3. M. L. Bauccio, ASM Metals Reference Book, 3rd Edition (ASM International, Materials Park Ohio, 1993)

4. H. E. Boyer, Selection of materials for service environments: Source Book (ASM International, Materials Park Ohio, 1987)

5. ASM International, Handbook Committee, Properties and Selection--Irons, Steels, and Highperformance Alloys, Vol. 1 (ASM International, Materials Park Ohio, 1990)

6. H.F. Xu, J. Zhao, W.Q. Cao, J. Shib, C.Y. Wang, C. Wang, J. Lia, H. Dong, Mater. Sci. Eng. A 532 (2012)

7. T. Tsuchiyama, T. Inoue, J. Tobata, D. Akama, S. Takaki, Scr. Mater. 122 (2016)

8. L. I. Parfenov, G. A. Sorokin., Met. Sci. Heat Treat. 13, 5 (1971)

9. H. Huang, O. Matsumura, T. Furukawa., Retained austenite in low carbon, Mat. Sci. Technol. 10, 7 (1994)

10. S. K. Putatunda, Mater.Des. 24, 6 (2003)

11. B. K. Zuidema, D. K. Subramanyam, W.C. Leslie, Metall. Trans. A 18, 9 (1987)

12. N. Ya. Samarin, R. Z. Kats, V. A. Startsev, I. A. Petrova, Met. Sci. Heat Treat. 23, 1 (1981)

13. J. L. Cao, A. M. Zhao, J. X. Liu, J. G. He, R. Ding, J. Iron Steel Res. Int. 21 (2014)

14. B. Steenken, J. L. L. Rezende, D. Senk, Mater. Sci. Technol. 33, 5 (2017)

15. Z. M. Ding, S. J. Wang, F. Yang, Y. Yan, Trans. Mater. Heat Treat. 28 (2007)

16. I.I. Kleshcheva, E.A. Shur, Metalloved. Term. Obrab. Met. 1 (1990)

17. J. Y. Liu, Y. S. Wu, L. Wei, S. B. Wang, T. Yan, W. D. Liu, J. Mater. Eng. (Chinese) 3 (2003)

18. L. Dong, Z. Ding, B. Liang, Z. Xu, Phase Transit. 88, $11(2015)$ 
19. W. Cheng, Y. Li, Metall. Mater. Trans. A 43, 6 (2012)

20. V. M. Dusevich, E. A. Shur, I. A. Semenov, Met. Sci. Heat Treat. 31, 9 (1989)

21. P. L. Gruzin, V.I. Grigorkin, V. V. Mural, L.N. Moskaleva, Met. Sci. Heat Treat. 11, 1 (1969)

22. E. R. Magdaluyo, Jr., Marthony, S. Ausa, R.I. Tinio, Transactions on engineering technologies (Springer, Singapore, 2016)

23. W. D. Callister, D.G. Rethwisch, Fundamentals of Materials Science and Engineering : An Integrated Approach (Jhon Wily \& Sons, Hoboken, 2011)

24. G. F. Vander Voort, Metallography, Principles and Practice (ASM International, Materials Park Ohio, 1999)

25. D. Andrews, G. Scholes, G. Wiederrecht, Comprehensive Nanoscience and Technology, 1st edition (Elsevier B.V., Amsterdam, 2010)

26. J. Chapman, F. Regan, T. Sullivan, Nanoparticles in Anti-microbial Materials: Use and Characterisation (RSC publishing, Cambridge, 2012)

27. O. Ben Lenda, A. Tara, F. Lazar, O. Jbara, A. Hadjadj, E. Saad, Strength Mater. 52 (2020) 